\title{
The effect of information technology business alignment factors on performance of SMEs
}

\author{
Ali Mechman Slim ${ }^{\text {a }}$ Omar Siti Sarah ${ }^{\text {a }}$, Kadhim Ghaffar Kadhima, Bashar Jamal Alia, Ahmed Moham- \\ med Hammood $^{\mathrm{a}}$ and Bestoon Othman ${ }^{\mathrm{b}^{*}}$
}

${ }^{a}$ Faculty of Technology Management and Business, Universiti Tun Hussain Onn, Malaysia

${ }^{b}$ Department of Business Administration, Koya Technical Institute, Erbil Polytechnic University, Erbil, Iraq

\begin{tabular}{l}
\hline C H R O N I C L E \\
\hline Article history: \\
Received: September 20, 2020 \\
Received in revised format: \\
October 102020 \\
Accepted: October 16, 2020 \\
Available online: \\
October 16, 2020 \\
\hline Keywords: \\
IT-business alignment \\
Strategic alignment model \\
Iraq \\
Small and midsize enterprises
\end{tabular}

Small and midsize enterprises

\begin{abstract}
A B S T R A C T
Strategic IT-business alignment is being expanded by researchers and professionals owing to its beneficial effect on the performance of SMEs. Luftman (2000) [Luftman, J. (2000). Assessing business-IT alignment maturity. Communications of the Association of Information Systems, 4(14), 1 50.] created the Strategic Alignment Model (SAM), which integrates various alignment viewpoints to offer a cohesive perspective on IT-business alignment. While SAM was widely implemented for western IT studies by theoreticians and practitioners, its adoption is not evident in the Middle East with few available studies. The goal of this gap is to examine the effect of small and medium-sized enterprises (SMEs) in Iraq of three alignment styles (communication, governance and competency) listed in SAM. The findings of the current study verified the beneficial effect of all sorts of IT alignment centered on a survey of 228 owners, IT managers, but the latter has also shown a strong positive influence across various types of alignment. Theory and implementation implications are addressed, and more research recommendations are suggested.
\end{abstract}

(C) 2021 by the authors; licensee Growing Science, Canada

\section{Introduction}

For many years now, the strategic IT-business alignment is known as one of the critical management concerns (Gerow et al., 2015; Luftman \& Ben-Zvi, 2011; Orozco et al., 2015). Studies also documented several beneficial consequences of such an alignment, like increased operating efficiency, innovation as well as potential competitive advantages, and ultimate improvement in output. At the same time, failing to align will contribute to adverse results like a waste of resources, worse financial efficiency, and organizational results (Alaceva \& Rusu, 2015; Chen et al., 2010; Ravishankar et al., 2011). Alaceva and Rusu, (2015) claim that alignment is to the degree to which the IT strategy communicates and promotes its purpose, goals and strategies. It has been indicated that the administration of IT is a way that represents management (Majstorović, 2016). Mosthaf and Wagner (2016) concluded that IT strategical alignment occurs where the objectives and practices of a corporation and the associated information structures are in agreement. Precise alignment suggests that in all cases, the organization implements sufficient IT, and these steps stay consistent with the company's strategic plans, priorities and demands (Liang et al., 2017). The very close alignment of IT and business strategies contributed to lower competitive stability and a reluctance to adapt in an appropriate way to environmental changes, according to Benbya and McKelvey (2006). About the fact that academics and professionals appear to be struggling to come together with the same perspective on IT-business coordination, specific frameworks have been implemented more often because of their reliability, relevance and robust psychometric behavior. As a foundation for higher strategic IT research, Luftman (2000) established the Strategic Alignment Model (SAM) (Coltman et al., 2015; Gutierrez et al., 2015). Nevertheless, the applicability of SAM to Middle East organizations is little known (for a rare example of research, see Alyahya and Suhaimi (2015).

\footnotetext{
* Corresponding author.

E-mail address: bestoon.othman@epu.edu.iq (B. Othman) 
Communication is one of the critical factors that link the IT Business Alignment and firm performance, but there are still some issues on communication in SMEs in Baghdad, Iraq. According to Hussein (2011) in Iraq, there is no channel for communication for business IT executives and shortage of formal networks to share their experiences with other units. Confidence and knowledge across corporate areas and IT divisions are reported that IT workers and down employees in the company had a lack of coordination, but only top management dominates (Ahmed et al., 2016). This can be seen when most of the companies do not have a page or website to promote their products to provide information about their background company. IT Competency at this point is the lower perception of IT value rather than IT cost. Most of SMEs in Baghdad state, Iraq concerned about the cost instead of the results that they will get back if they apply IT business alignment through their company or business, however, even fewer productivity measures may be triggered by internal and outsourced IT (Alkhaffaf, 2018). In Baghdad Iraq, they do not use business and IT metrics continuously, Lack of direct link between the company and IT metrics, no consistent internal and external benchmarking. This is because they still use the traditional method, which is also caused by their financial, that they do not get support from the government to encourage them in IT, Little to no applied IT and business perspective in contrast with other countries. It has been emphasized by Alkhaffaf (2018), Al-lamy (2018) and Altalib et al. (2018).

Acknowledging the issues identified above, thus it is imperative to investigate Competency and its influence on SMEs performance of Iraq. In Baghdad, the capital city of Iraq, SMEs had difficulties running their businesses, like weak IT-Non-IT ties with the perception of customer needs. Only IT staff will be exposed about the importance of IT in business, for other departments they only focus on their work without knowing that they also need to apply IT in their duty to improve their company and skill (Abbas, 2007). Partnership in business, the partner also holds an essential part in business success, but the uncertain responsibility and position among businesses and IT workers internally is often the issue they have faced particularly among SMEs in Baghdad (Bandiera et al., 2019). So many disputes and distrusts occur between the company and IT managers and, in the preparation and execution process, cost and benefit-sharing among companies and IT are segregated. They still may not treat IT as a business associate. This has been highlighted by Harash et al. (2014), acknowledging the issues identified above. Thus, it is crucial to investigate partnership and its influence on SMEs performance of Iraq. Therefore, the objective of this study is to review the elements of (communication, governance, Competency and partnership) and their roles as IT Business Alignment Factor in Iraqi companies.

\section{Literature Review}

\subsection{SMEs Performance}

A strong view of SMEs' output as the main based framework of this study is inevitable, in particular in terms of the concept of the company itself and its SMEs. The assessment of small and medium companies' output is the key to strategic management (Santos \& Brito, 2012). Nevertheless, there is not a commonly agreed concept of corporate performance because it is a complex and multi-dimensional object. A wide array of metrics measuring SMEs' success have been identified and utilized by academic researchers. Also, these metrics could be categorized as objective and subjective (Belderbos et al., 2004). The following describes and addresses in depth these various metrics of the performance of SMEs. In reviewing previous studies, Martin assessed three types of SMEs performance, namely, financial performance, productivity, and customer benefit (Martin et al., 2017). Financial performance refers to the potential of the company to generate more income by increasing its competitive advantage (Ashrafi \& Mueller, 2015). Secondly, productivity is a measure of the contribution of various input processes into output (Luftman et al., 2017). Finally, the total benefit received by stakeholders from the utilization of a particular IT service offering is known as customer benefit (Brynjolfsson \& Hitt, 2000). Business success driven by IT allows companies to gain benefit through IT investments and only by successful IT business alignment can they prosper. To fully show success (Schwarz et al., 2010), there will always be a tangible result. SMEs performance is one of the main pillars of management research. According to Homburg et al. (2019), the concept of business performance may differ in two areas: a) financial output (profit, return on assets, expenditure gain, etc.). (b) organizational performance covers three different areas of organizational performance. (b) Economic performance of goods (sales, market position, etc.). And (c) return on shareholders (total return on investments, additional value for the economy, etc.). SMEs, on the other hand, may often calculate efficiency from a perceived approach to performance, where Likert-like scale is employed to test the efficiency of small and medium-sized companies from the top management point of view. In general, financial performance represents the effects and trends of the business sector that illustrate the general financial stability of the industry over time. It shows how efficiently an organization manages its resources to optimize its shareholder equity and competitiveness. At the same time, a full calculation of the financial efficiency of an SME takes into consideration several other forms of metrics. However, the financial ratio is the most common measurement of performance utilized in finance and inference statistics (Huo et al., 2016).

\subsection{Communication}

The communication element is needed for alignment and is deemed valid if the receiver understands the information from the sender (Adnan \& Jambari, 2016). Over the last few years, development over ICT has been swift and there are some evidence of substantial changes in practices like the Supply Chain Management (SCM) under which positive outcomes can still be obtained in the management of equipment (Biniazi et al., 2011). 
Communication technologies have a beneficial effect on the success of SMEs, current socio-economic conditions within the districts under which businesses often affect communications technology preference and significantly shape the influence of communications technology on business performance, and communication technologies tend to play a more valuable and substantial role on local economy growth (Rufai, 2014). Leadership, support from senior management and good working relations also form part of effective communication (Navedo-Samper et al., 2013). Knowledge and information that is appropriately passed between management and employees also affects the attitude and eagerness of employees to participate and make a success of the alignment process through the achievement of business goals, curb resistance from both users of IT services and IT employees, intentions and goals have to be effectively communicated such that they are understood by those who receive the information (Reilly et al., 2006). To foster cooperation, people need to understand their roles and what is required of them. At an operational level, business units have to have a shared perspective on what business processes are in place to achieve operational objectives, and these ultimately will support the overall business objectives (Tarhini et al., 2015). It is a management role to communicate what processes are needed to support a particular function, and through IT processes management will help effect that business process (Rath, 2018). The communication is chosen to be one of the factors become of its essential role that has been mentioned by many authors explained earlier — stated that communication is considered as an essential element to adopt factors of IT-business alignment. Many Scholars (e.g. Luffman, 2000; Poelen; Stamper et al., 2012) have identified that communication is one of the essential factors that link between the IT business alignment SMEs performance. This has been highlighted by the other researchers such as (Helaly, 2012; Naidoo, 2011; Gutierrez et al., .2009; Sledgianowski \& Luftman, 2005) who claimed that communication leads to the successful company. Therefore, communication is chosen to be one of the factors that become of its essential role that has been mentioned by many authors explained earlier.

\subsection{Governance}

IT governance is one structure whereby the position of IT could be adequately identified in organizations and how every IT work can achieve its business goals is paramount (De Haes \& Van Grembergen, 2005). Governance reports on the implementation of other tasks and on how they are defined as objectives and how they can be strengthened (Rigoni et al., 2010). There were four problem areas which separated a potential reason for the IT-business discrepancy (Wagner et al., 2015). The four areas are issues of leadership, structure, process, level of service and principles. The governance role of IT and business managers are a source of these four areas (Tarhini et al., 2015). The connection between IT and business leaders should be built in order to promote the effective incorporation of the IT strategy and plans in the integration phase and a suitable framework and procedure (Malyzhenkov \& Ivanova, 2017). Quality in terms of stakeholder satisfaction with IT initiatives also helps bridge the gap, without business leaders believing that IT is a crucial part of business, their initiative will hold no value in business (Sahin \& Robinson, 2002). Also indicated that implementations of a governance framework such as ITIL (IT Infrastructure Library) also helps in bridging the IT-business alignment gap as some of the problems above are dealt with (Marrone \& Kolbe, 2011). A framework defines the structure, quality and adoption of technical services in an organization. Business process excellence in the context of IT governance initiatives can be achieved through implementation and measurement of IT outputs in support of non- IT business functions and processes (Debreceny et al., 2013). This is driven through the IT capability maturity model in which the ideal status being targeted is the optimized processes which are clearly defined, fully documented, and they are repeatable (Lacerda \& von Wangenheim, 2018). Repeatable processes improve efficiency, as they can be reused across business domains (Kumar \& Harms, 2004). IT governance is one of the essential factors that can help organization, many researchers such as (stamper et al., 2012; Heroux \& Fortin 2018; luftman, 2000) have identified that governance is one of the critical factors that link between the IT business alignment MEs performance. This has been highlighted by others (Shamekh, 2008 Naidoo, 2011; Sledgianowski \& Luftman, 2005) who asserted that governance leads to the successful company. Therefore, governance is chosen to be one of the factors that become of its essential role that has been mentioned by many authors explained earlier.

\subsection{Competency}

Organizations use their accounting reports, the efficiency of their goods, manufacturing expenses etc. so they need internal records. Thus, it requires external environmental information, which lets them know more about and please their consumers quickly and efficaciously - from competitions, buyers, vendors and so on, to achieve strategic advantages in the sustainable environment (Lai et al., 2006). This research after Tippins and Sohi (2003) defines IT abilities to how the organization employs such technologies to control its information successfully. Whereas IT is a common word used primarily for programs, computers and telecommunications, it applies to the usage of the competence to meet the company's information requirements when applying to such technologies (Mithas et al., 2011). IT competence has gained new urgent significance in terms of competency concerning the resources and procedures used to manage information, despite the growing value of information in the world marketplace of today (Glazer 1991). Competences are inimitable from a resource-based point of view owing to the uncommon emergence of resources that has no interest in a single market setting. The competitive advantage could be founded on this inimitability (Lei et al., 1996). Therefore, organizations with higher IT skills are deemed superior in the management of the 'invisible assets' that establish market leadership (Itami \& Numagami 1992). From their marketing literature (Glazer, 1991), strategy (Leonard-Barton, 1995), and IT (Mitcham and Mackey, 1983; Taylor, 1971), they build IT competencies to allow an IT firm competent and efficient at managing information within a business. It is believed that businesses include IT-objects (e.g. applications, equipment, and IT staff) even in this understanding of the concept. The consolidated 
three dimensions of IT competency, IT knowledge, IT operations, IT infrastructure include co-specific resources that demonstrate the organization's capacity to identify and utilize IT technologies and processes required for the management of the business and consumer data.

\subsection{Partnership}

Several empirical experiments were carried out to assess the association between performance and partnership with various results. Stuart (2000) published a development and innovation analysis addressing the developing technology sector to investigate the benefits of portfolio collaborations and the conclusions that businesses had more reliable outcomes than others lacking broad and creative collaborators. More experiments to test two models were suggested in the report. Jonathan and Soldi (2011) found that active collaborations are those that fulfil the aims of the partnership to create a win-win condition in order to assess the effectiveness of alliances in the financial services field. This study centered on the service industry and suggested more research for further generalization of other industries. In a case study by the Equity Bank, Kudate (2014) surveyed to determine the impact of SME and big business strategic partnerships and found that although collaboration is a reasonable choice, small businesses need more information before joining partnerships. The researcher has proposed further work on governing and operating organizations. Walekhwa (2011) proposed more research in agency banking in a review of the Equity Bank and its collaborators on the impact of decision-making partnerships. Such studies show that knowledge gaps also remain and need further analysis of advances on how partnerships are organized and how organizations respond to different needs.

\subsection{Hypotheses Development and Research Framework}

The conceptual framework and hypotheses are generated from the SAM (Luftman, 2000). The strategic alignment model (SAM) is by current literature (i.e., Gutierrez et al., 2008; Sledgianowski et al., 2006; Hussin et al., 2002). SAM has a significant effect on the performance of Iraqi SMEs. The research proposes four hypotheses which are presented next. Because of IT business alignment factors (communication, governance competency and partnership), some other combinations of strategies are likely to be expected and might influence the performance of SMEs. Influences such as communication, managerial abilities and partnership can also be direct. Communication refers to direct influence on SMEs performance; governance refers to direct influence on financial performance; competency refers to direct influence on financial performance, And the level of service relates to direct economic effects. Sledgianowski et al., 2006; Hussin et al., 2002 empirically verified these main impacts. This research also examined potential direct influences of alignment factors, in keeping with these results. This is also aimed at presenting accurate and applicable information. The following hypothesis is offered based on this:

\section{$\mathrm{H}_{1}$ : Commination has a significant influence on SMEs performance.}

Internal communication, according to Rajhans (2012), has a very critical function in executing all this organization's desired motivational activities. Effective communication helps increase the morale and efficiency of workers in the business. Muchlas (2012) clarified in favor of this argument that communication has increased the motivation by communicating to the staff what they need to do and how they need to achieve and what they should do to improve their efficiency. Another theory from Linkert describes how inspiring and efficient would be if we (leaders) have productive relations with workers (Littlejohn et al. 2005). In a certain sense, effective communication between managers and workers will build an incentive for work that increases performance. Femi (2014) work indicates that the connection between communication and employee success is successful because excellent communication provides a shared trust between the management and employees that tends to establish positive relationships between the two parties inside the company. This study indicates that inadequate communication may impact the output of employees. Rukmana et al. (2018) stated that the relationship between employee success relationship in Indonesia has been excellent.

\section{$\mathrm{H}_{2}$ : Governance has a significant influence on SMEs performance.}

Better corporate governance is widely believed to boost efficiency for SMEs (Buallay et al., 2017). Despite the generically agreed notion that good corporate governance improves the organizational efficiency of companies, other research recorded the adverse association between organizational governance and SMEs' success (Hutchinson \& Gul 2004). Others also suggested that the limitation of usage of either publicly accessible data or survey data can become part of the issue (Ward et al. 2009). The explanation for these inconsistencies is many and differs. It was also noticed that this difference might also be caused by the design of the performance measures (i.e. restricted usage of accounting indicators, like return on assets (ROA) or equity return, return on employed capital (ROCE), or restricted use of business-based actions (such as stock market value), (Berthelot et al., 2010). To tackle some of these issues, it is suggested to take these issues into account in looking at corporate governance and its connection with the success of SMEs.

\section{$\mathrm{H}_{3}$ : Competency has a significant influence on SMEs performance.}

The capacity to mimic or replace competitors for competence in combination with specific organizational skills will produce a synergist influence, which is far harder (Alvarez-Suescun, 2007; Sher \& Lee, 2004). Therefore, the IT literature has proposed 
that the IT performance partnership must be associated with contingencies (Tippins \& Sohi, 2003). Considering the value provided to IT skills as a critical contributor to processes related to knowledge administration and the reality that processes of knowledge and knowledge management are associated with business performance (Mills \& Smith, 2011). We anticipate IT competency to affect not explicitly but implicitly on the company's performance by information management processes. Small and medium-sized companies could hardly improve their output by investing in IT technologies alone because they may be readily accessed and imitated (Tippins \& Sohi, 2003). In comparison, because the company is willing to utilize the IT systems and IT activities for successful information control procedures to exploit its IT expertise, it would be able to achieve an improvement in market performance metrics and thus in financial efficiency.

\section{$\mathrm{H}_{4}$ : Partnership has a significant influence on SMEs performance.}

Partnership relates to the degree of partnership between IT and companies. It involves describing the role of IT in corporate decisions, the degree of confidence and the understanding of every other's participation. This is necessary for the IT role to work closely with business activities, which will improve shared trust, develop reasonable objectives and establish successful relationships. Alignment of cross-functional teams, who build mutual partnerships that help to recognize and follow specific objectives contributes to the exchange of challenges and rewards, is, therefore, more simple (Luftman et al., 1999). The desire for collaboration and the improved importance of more robust partnerships should be taken into consideration by both IT and organizational management (Keen, 2007; Luftman et al., 1999; Bassellier \& Benbasat, 2007). The relationships are crucial to deciding the outcome of arrangements between companies (Wen-Chih et al., 2017). The relationship interactions suggested by Bower (2018) help to boost company efficiency. Close cooperation ties between collaborators have a beneficial influence on the efficiency of the partnership (Rezaei et al., 2018).

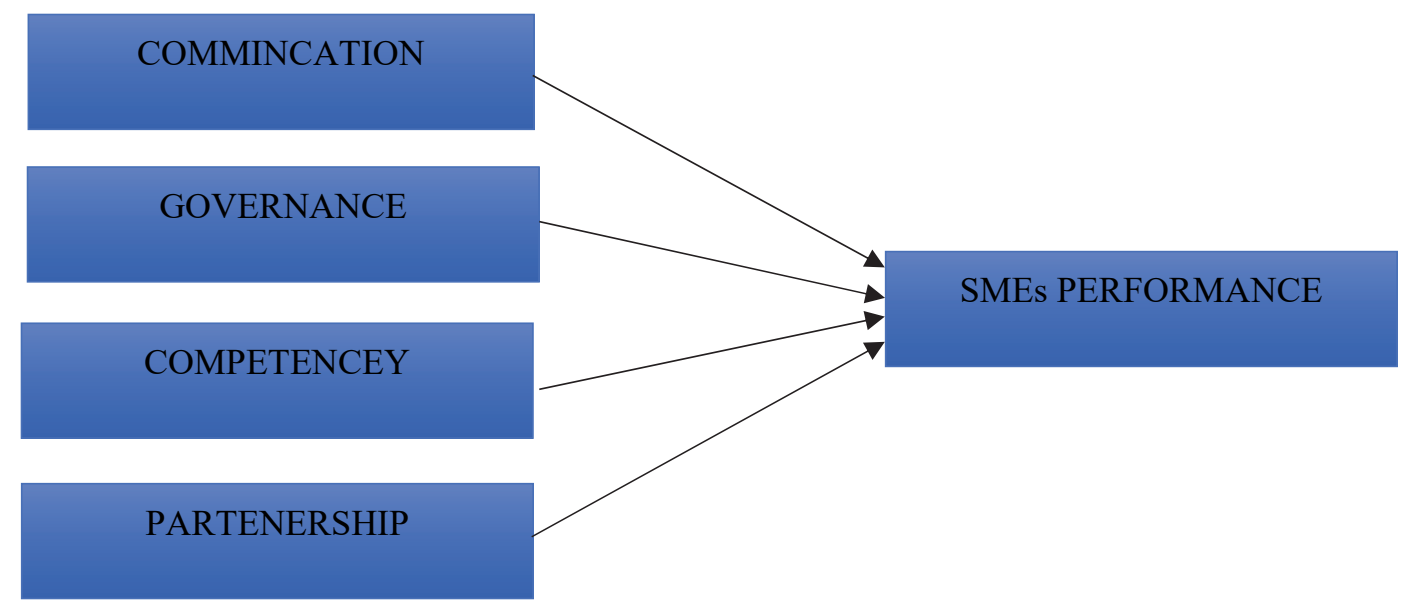

Fig. 1. Model of IT Business Alignment factors, SMEs Performance

\section{Methodology}

In this study, an attempt is made by the researcher to gain insight into the correlation between different variables to find a fitted model. Therefore, to achieve this, the researcher applied a deductive approach to hypothesis testing. The quantitative method was employed in this research to accomplish the aims of the study. Using the design, the study type, methods of data collection and method of data analysis are planned because the study seeks to investigate the influence of IT business alignment factors (communication, governance, competency and partnership) on SMEs performance in Baghdad. As a consequence of the constraints of this analysis, a cross-sectional investigation was conducted. More so, this study is also a correlational study which aims at studying the correlation between the variables under study. The data is obtained by the survey method and then analyzed using Smart PLS.

This study performed a survey to investigate the conceptual model, the problems of research and relevant hypotheses. The survey was carried out among owner, managers and IT staffs in SMEs. For the collection of data, a questionnaire containing relevant questions was designed by the researcher. The aim of designing this questionnaire is to obtain relevant information that can provide more insight into the phenomenon under study. According to Sekaran (2003) questionnaire has some advantages, which include, low cost and time required to reach out to a more significant number of individuals. According to this scholar, the use of a questionnaire is more accessible than the collection of qualitative data using interview, which requires more skills. Dillman and Smyth (2007) noted that the questionnaire is one of the well-established instruments of data collection in social science research. The questionnaire used in this study contains measurement scales which were adopted from previous studies and thorough review of the literature. The kind of questionnaire used in this study is a Likert scale-type. According to Hair, Wolfinbarger, Ortinau, and Bush (2008), the use of Likert scales is most appropriate when the survey 
instrument is self-administered. Due to the ease of administering the Likert-scale kind of questionnaire, it has become prevalent and widely-used (Zikmund, 2003). Even though it is acceptable to adopt and adapt a questionnaire to suit the current study, changes to the instrument may impact the instruments' validity and reliability. In this study, the use of a questionnaire was employed in obtaining data from the selected sample within the Baghdad city of Iraq. Based on the suggestion of Sekaran \& Bougie (2016), As the researchers have information of what is expected as well as the measurement of variables under analysis, a structured survey has been used as an appropriate sampling collection method. The survey includes various sections documenting the respondents ' demographic characteristics and questions on the dependent variable (SME's performance) and independent variables. The section which contains questions related to the independent variables for measuring the dimensions of IT business alignment factors (communication, governance, competency and partnership).

Table 1

The Questionnaire's Sources

\begin{tabular}{lc}
\multicolumn{1}{c}{ Sections } & Sources \\
\hline Communication & (Luftman \&Lyytinen, 2015) \\
Governance & Gutierrez et al., 2015) \\
Competency & \\
Partnership & \\
\hline
\end{tabular}

\section{Results and Discussion}

This section presented the description of participating companies. As discussed previously, the population of this research was Iraqi services SMEs. The criteria of the companies that participated were SMEs that implemented e-commerce, whereas the targeted respondents were only the owners, managers, and IT staffs specifically. The characteristics examined included gender of respondents, age, level of position, Size of company, education level, marital status as well as years of working. SPSS software version 22.0 was used to analyse the profile of the participants. The study findings of the research participants' profile are summarized in Fig. 2.

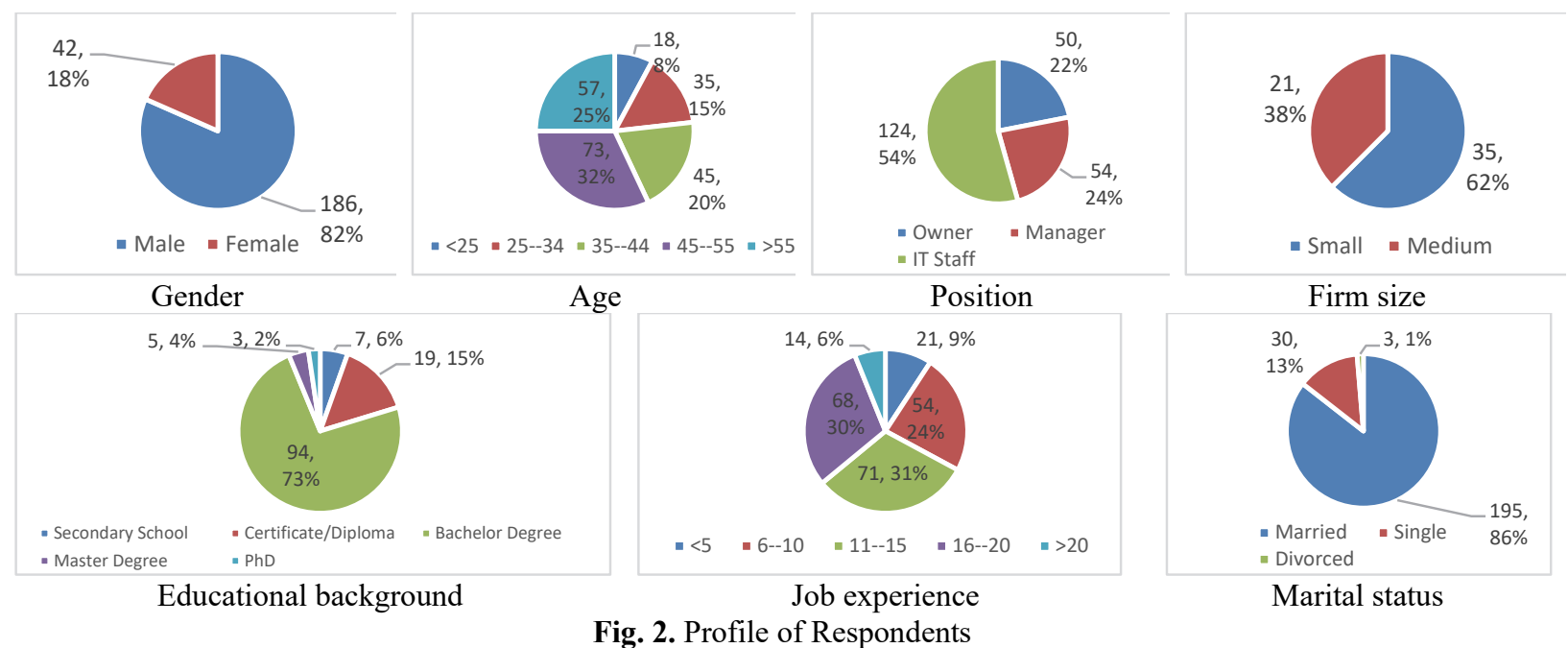

The 228 participating respondent profile were analyzed, and the frequencies and percentages were obtained. In this research, the gender of respondents had been assessed, and it was found that $81.6 \%$ of the respondents were males, and only $18.4 \%$ were females. Furthermore, the age of the respondents was also included, and the results obtained showed that majority of the respondents with a percentage of $32 \%$ were within the age range of 45 to 55 years old. The second highest group were respondents with an age range of above 55 years old with a percentage of $25 \%$, followed by the third-highest percentage of $19.7 \%$ hold by respondents with an age range between 35 to 44 years old, $15.4 \%$ were respondents with an age range between 25 to 34 whereas the last group which obtained the least percentage of $7.9 \%$ were respondents younger than 25 years old. Next, the level of position of respondents was also taken into account. Achieving the highest percentage of $23.7 \%$ was managers, followed by IT staffs with a total percentage of $54.4 \%$ and lastly with the least percentage of $21.9 \%$ were respondents who worked as owners. Next, from the descriptive statistic, the researcher had also provided an item to measure the department the respondents were in. The size of the company of the respondents was also assessed, and it was found that majority of the respondents were a small company with a total percentage of $62.5 \%, 37.5 \%$ of the respondents from Medium company. Moreover, the descriptive statistics applied as well as measured the education level of the respondents. Most of the respondents with a total percentage of $1.3 \%$ were found to be a Master's degree holder, $62.2 \%$ of the respondents were a Bachelor degree holder, $24.6 \%$ holds a certificate or a diploma, $2.2 \%$ of the respondents were certified as a PHD holder. Only $9.7 \%$ of respondents were found to have an educational background with only a secondary school certificate. Furthermore, Marital status 
of participants was also evaluated, and the majority of them were married with $85.5 \%$ total rate, of which $13.2 \%$ reported to be single, $1.3 \%$ stated as divorced whilst $0 \%$ of the respondents purported as a widow. The final part of the profile analysis showed the results of the working years of the respondents. Numbers of respondents with a total percentage of $31.1 \%$ claimed that they had served 11 to 15 years of working service to their company, $23.7 \%$ of the respondents had worked for 6 to 10 years, and, and $29.8 \%$ of the respondents had worked for 16 to 20 years, $9.2 \%$ had working experience of 5 years only, and the minority of the respondents with a percentage of $6.1 \%$ had working experience of 20 years and above.. The data gathered is reliably examined. The available data from 228 participants were collected in this analysis. Cronbach's Alpha, as indicated by Sekaran \& Bougie (2016), was used to calculate the reliability of the instruments employed. For this analysis, the reliability of all items has been checked and, in order to be appropriate, Cronbach will have an alpha value of at least 0.70 , according to Pall ant (2013). Throughout this study, 228 respondents were randomly selected as participants in this research, as already stated. The reliability of all items of all scales was defined, and the findings showed strong reliability in all measurements. The corresponding alpha values of Cronbach are seen in the following table in the sample with $\mathrm{N}=228$.

Table 2

Cronbach's Alpha Values

\begin{tabular}{cccc}
\hline No. & Variables & Cronbach's Alpha & Variance Extracted (AVE) \\
\hline 1 & Communication & 0.892 & 0.891 \\
2 & Governance & 0.886 & 0.681 \\
3 & Competency & 0.910 & 0.679 \\
4 & partnership & 0.865 & 0.727 \\
5 & SMEs performance & 0.709 & \\
\hline
\end{tabular}

Note: For every item, the AVE values should be at or above 0.50 to have a satisfactory validity for the convergence (Fornell and Larker, 1981 ).

Table 2 indicates that the robust Cronbach Alpha has been reached by all items in this analysis as all items reached are above 0.7. Therefore, in testing the model presented in the analysis, the scales were shown to be reliable and can be used.

Convergent validity is used to explain to the degree the metrics within a particular structure converge on a large degree within overall variance (Hair, Black, Babin \& Anderson, 2010). An AVE, Composite Reliability (CR) and Factor Loading evaluation, as proposed by Hair et al. (2010) was carried out. As stated by Hair et al., (2010), and AVE of 0.5 or higher is a good Convergence Validity; an average load is 0.7 or higher, and a CR of 0.7 or higher. The AVE values for all the constructs varied between 0.695 and 0.740 based on the outcome in Table 2, which surpassed the required level of 0.5 . This finding indicates that the validity of the measurement model of the sample is adequate. In addition to maintaining the distinguishing validity of the measuring model, the cross-loading measurement was tested following the measurement standards criterion of Fornell-Larcker in 1981. By trying to compare the Square root of the average variance extracted (AVE) with the relationships of other variables, the discriminant validity was established. Late variable correlations (LVCs) are anticipated to be not higher than every latent variable. Table 2 also displays the AVE root square for aspects of IT alignment (communication, governance, competencies and partnership) and performance of small and medium-sized companies.

Table 3

Fornell-Larcker's criterion

\begin{tabular}{cccccc}
\hline Construct & COM & COMP & GOV & PAR & SMEP \\
\hline COM & $\mathbf{0 . 9 5 5}$ & & & & \\
COMP & 0.825 & $\mathbf{0 . 9 1 3}$ & & \\
GOV & 0.937 & 0.824 & $\mathbf{0 . 9 9 0}$ & 0.937 & 0.952 \\
PAR & 0.905 & 0.855 & 0.968 & 0.842 \\
SMEP & 0.834 & 0.705 & 0.858 & \\
\hline
\end{tabular}

The current study used the evaluation of the structural model to validate the hypotheses that have been proposed. Besides, Hair et al. (2011) indicated that an approved path coefficient would be at minimum 0.1 , at a reasonable coefficient of at least 0.05 (or $95 \%$ confidence level), to preserve the path coefficient to the suggested model. The level of significance and acceptance of hypotheses was determined using the values obtained from the bootstrapping procedure, which was performed using SmartPLS 3.0. The t-values which were obtained using SmartPLS 3.0 bootstrapping at 228 re-samplings were used to determine the significance of the hypotheses for all constructs. The following positive direction was advocated in this study: To analyze the impact of the variables for IT (communication, governance, competency and partnership) on SMEs performance. Based on the statistical assessment of the path coefficients, it is only when the t-value is more significant than 1.96 that the hypothesis will be accepted and supported (Hair et al., 2017). Table 4 demonstrates the results of the tested hypotheses, which shows that all the four hypotheses that were tested to determine the direct effect were supported and there was a significant favorable influence. Result of direct effect for the supported hypotheses including H1) the positive influence of communication on SMEs performance $(\mathrm{t}=231.145 ; \mathrm{p}<0.001), \mathrm{H} 2)$ the positive influence of governance on SMEs performance $(\mathrm{t}=165.170 ; \mathrm{p}<0.001), \mathrm{H} 3)$ the positive influence of competency on SMEs performance $(\mathrm{t}=101.485 ; \mathrm{p}<0.001), \mathrm{H} 4)$ the positive influence of partnership on SMEs performance $(\mathrm{t}=79.885 ; \mathrm{p}<0.001)$. 
Table 4

Results of Hypotheses Testing (Direct Relationship Results)

\begin{tabular}{cccccc} 
& Relationship & $\begin{array}{c}\text { path } \\
\text { No }\end{array}$ & $\begin{array}{c}\text { Standard Deviation } \\
\text { (STDEV) }\end{array}$ & $\begin{array}{c}\text { T Statistics } \\
(\mid \mathbf{O} / \text { STDEV) }\end{array}$ & p-value \\
\hline H1 & communication $\rightarrow$ SMEs Performance & 0.977 & 0.004 & 231.145 & 0.000 \\
H2 & governance $\rightarrow$ SME Performance & 0.970 & 0.006 & 165.170 & 0.000 \\
H3 & competency $\rightarrow$ SME Performance & 0.953 & 0.009 & 101.485 & 0.000 \\
H4 & partnership $\rightarrow$ SMEs Performance & 0.940 & 0.012 & Supported & Supported \\
\hline
\end{tabular}

\section{Conclusion}

One of the topics that have emerged as a relevant topic in the field of marketing is IT business alignments factors as there is an increase in the interest of practitioners and business theorists in the area of ITBA, as well as its implications for SMEs. Findings of the study revealed that SMEs performance is influenced by IT business alignment factors (Communication, Governance, Competency, Partnership), and as such should be considered by SMEs as a useful marketing tool in Iraqi SMEs. The result of the statistical analysis confirmed that the primary research hypotheses were accepted. Also, the result showed that ITBA factors (Communication, Governance, Competency, Partnership) have a positive impact on the performance of SMEs towards a product or a business. Even though the study was successfully carried out, there are some limitations associated with the study, and based on those limitations, suggestions for future study were given. The research applies to the area of marketing through the analysis of the relationship between ITBA variables and SME outcomes in small and medium-sized enterprises. One of the significant ways through which a sustainable competitive advantage can be built is by ensuring SMEs performance. In this study, the role of ITBA factors in enhancing SMEs performance in Baghdad city of Iraq. More so, the association between ITBA and the performance of SMEs has been explored in this study. Such research results have several practical and theoretical implications. The results of the analysis indicate that a higher degree of ITBA has a significant effect on the efficiency of SMEs. The perception which customers have about ITBA is essential and has implications for customers. More robust evaluations of SMEs can result from the expectations which customers have towards ITBA factors for customers to demonstrate intentions to repeat business firms if they must increase their ITBA so that customers can develop favorable attitudes, thereby resulting satisfaction. This research helps to understand the overall level of ITBA in SMEs by providing insight into how ITBA influences SMEs performance. Therefore, it can be concluded that sustainable competitive advantage can be built to develop the SMEs performance. This means that if a firm carries out extensive ITBA factors, the perceptions of customers towards SMEs will be positively influenced.

\section{Acknowledgement}

We would like to express our greatest gratitude to the Research Management Centre Fund E15501 of Universiti Tun Hussein Onn Malaysia, Batu Pahat Malaysia for funding the publication.

\section{References}

Adnan, N. M., \& Jambari, D. I. (2016). Mutual understanding determinants for effective communication in business and IT strategic alignment planning. International Journal on Advanced Science, Engineering and Information Technology, 6(6), 914-921.

Ahmed, S. M., Zakaria, M. S., \& Altemimi, M. A. H. (2016). CSFs of electronic information sharing in Iraqi SMEs. Journal of Engineering and Applied Sciences, 11(8), 1846-1850.

Alaceva, C., \& Rusu, L. (2015). Barriers in achieving business/IT alignment in a large Swedish company: What we have learned? Computers in Human Behavior, 51(B), 715-728.

Alkhaffaf, H. H. K., Idris, K. M., Abdullah, A., \& Al-Aidaros, A. H. (2018). The influence of technology readiness on information technology competencies and civil conflict environment. Indian-Pacific Journal of Accounting and Finance, 2(2), 51-64.

Al-lamy, H. A., Bakri, M. H., Teknikal, U., Al-shami, S. S. A., \& Alaaraji, Z. (2018). Information technology infrastructure and small medium enterprises' in Iraq. Opcion, 34(86), 259-285.

Alvarez-Suescun, E. (2007). Testing resource-based propositions about IS sourcing decisions. Industrial Management \& Data Systems, 107(6), 762-779.

Alyahya, M., \& Suhaimi, M.A. (2013). A conceptual model for business and information technology strategic alignment from the perspective of small and medium enterprises. International Journal of Business, Humanities and Technology, 3(7), 83-90.

Ashrafi, R., \& Mueller, J. (2015). Delineating IT resources and capabilities to obtain competitive advantage and improve firm performance. Information Systems Management, 32(1), 15-38.

Bandiera, L., Chandra, V., Fosque, J., von der Goltz, J., Peterburs, T. M., Piffaretti, N., ... \& Wheeler, C. (2019). Jobs in Iraq: a primer on job creation in the short-term.

Bassellier, G., \& Benbasat, I. (2007, April). Assessing the Contributions of Business and IT Knowledge to the Development of IT/business Partnerships. In Proceedings of the 2007 ACM SIGMIS CPR conference on Computer personnel research: The global information technology workforce (pp. 203-206). ACM.

Belderbos, R., Carree, M., \& Lokshin, B. (2004). Cooperative R\&D and firm performance. Research Policy, 33(10), $1477-1492$.

Berthelot, S., Morris, T., \& Morrill, C. (2010). Corporate governance rating and financial performance: a Canadian study. Corporate Governance: The International Journal of Business in Society, 10(5), 635-646.

Bower, D. J. (2018). Company and campus partnership: supporting technology transfer. Routledge.

Brynjolfsson, E., \& Hitt, L. M. (2000). Beyond computation: Information technology, organizational transformation and business performance. Journal of Economic Perspectives, 14(4), 23-48. 
Buallay, A., Hamdan, A., \& Zureigat, Q. (2017). Corporate governance and firm performance: evidence from Saudi Arabia. Australasian Accounting, Business and Finance Journal, 11(1), 78-98.

Coltman, T.R., Tallon, P.P., Sharma, R., \& Queiroz, M. (2015). Strategic IT alignment: Twenty-five years on. Journal of Information Technology, 30(2), 91-100.

De Haes, S., \& Van Grembergen, W. (2005, January). IT governance structures, processes and relational mechanisms: Achieving IT/business alignment in a major Belgian financial group. In Proceedings of the 38th Annual Hawaii International Conference on System Sciences (pp. 237b-237b). IEEE.

Debreceny, R. S., \& Gray, G.L. (2013). IT governance and process maturity: A multinational field study. Journal of Information Systems, 27(1), 157-188.

Dillman, D. A., \& Smyth, J. D. (2007). Design effects in the transition to web-based surveys. American journal of preventive medicine, 32(5), S90-S96.

Femi, A. F. (2014). The impact of communication on workers' performance in selected organisations in Lagos State, Nigeria. IOSR Journal of humanities and Social Science, 19(8), 75-82.

Fornell, C., \& Larcker, D. F. (1981). Structural equation models with unobservable variables and measurement error: Algebra and statistics. Journal of Marketing Research, 18(3).

Gerow, J., Thatcher, J.B., \& Grover, V. (2015). Six types of IT-business strategic alignment: An investigation of the constructs and their measurement. European Journal of Information Systems, 24, 465-491.

Glazer, R. (1991). Marketing in an information-intensive environment: strategic implications of knowledge as an asset. Journal of Marketing, 55(October), 1-19.

Gutierrez, A., Orozco, J., \& Serrano, A. (2009). Factors affecting IT and business alignment: a comparative study in SMEs and large organisations. Journal of Enterprise Information Management, 22(1/2), 197-211.

Hair, Jr, J. F., Sarstedt, M., Ringle, C. M., \& Gudergan, S. P. (2017). Advanced issues in partial least squares structural equation modeling. Sage publications.

Hair, J. F., Bush, R. P., \& Ortinau, D. J. (2008). Marketing research. New York, NY: McGraw-Hill Higher Education.

Harash, E., Al-Timimi, S., \& Alsaadi, J. (2014). The influence of finance on performance of small and medium enterprises (SMES). Technology, 4(3), 161-167.

Helaly, M. (2012). The impact of IS/IT strategy and business strategy alignment on business performance in the Palestinians firms (Doctoral dissertation, Faculty of Graduate.

Henderson, J.C., \& Venkatraman, H. (1999). Strategic alignment: leveraging information technology for transforming organizations. IBM Systems Journal, 38(2/3), 472-484.

Héroux, S., \& Fortin, A. (2018). The moderating role of IT-business alignment in the relationship between IT governance, IT competence, and innovation. Information Systems Management, 35(2), 98-123.

Homburg, C., Wielgos, D., \& Kühnl, C. (2019). Digital business capability and its effect on firm performance. In AMA Educators' Proceedings (Vol. 30, pp. ICM-2). American Marketing Association; Curran.

Huo, B., Ye, Y., Zhao, X., \& Shou, Y. (2016). The impact of human capital on supply chain integration and competitive performance. International Journal of Production Economics, 178, 132-143.

Hutchinson, M., \& Gul, F. A. (2004). Investment opportunity set, corporate governance practices and firm performance. Journal of Corporate Finance, 10(4), 595-614.

Itami, H., \& Numagami, T. (1992). Dynamic interaction between strategy and technology. Strategic Management Journal, 13(S2), 119135.

Jonathan, C. D. \& Soldi, A. (2011). Strategic alliances; organizational performance measurement in the financial services industry; the beneficial life insurance SA and microfinance institutions in Cameroon. Unpublished MBA project, Linkoping University.

Keen, D. (2007). Parents, families, and partnerships: Issues and considerations. International Journal of Disability, Development and Education, 54(3), 339-349.

Kudate, V. N. (2014). Study on the influence of strategic partnerships between small and large businesses in organizational performance; the case of Equity Bank Agency banking. Unpublished MBA project. Nairobi: University of Nairobi

Kumar, S., \& Harms, R. (2004). Improving business processes for increased operational efficiency: a case study. Journal of Manufacturing Technology Management, 17(5).

Lacerda, T. C., \& von Wangenheim, C. G. (2018). Systematic literature review of usability capability/maturity models. Computer Standards \& Interfaces, 55, 95-105.

Lai, F., Zhao, X. and Wang, Q. (2006). The impact of information technology on the competitive advantage of logistics firms in China. Industrial Management \& Data Systems, 106(9), 1249-63.

Lei, D., Hitt, M. A., \& Bettis, R. (1996). Dynamic core competences through meta-learning and strategic context. Journal of Management, 22(4), 549-569.

Liang, H., Wang, N., Xue, Y., \& Ge, S. (2017). Unraveling the alignment paradox: how does business-IT alignment shape organizational agility?. Information Systems Research, 28(4), 863-879.

Littlejohn, S. W. \& Foss, K. A. (2005). Theories of Human Communication, $8^{\text {th }}$ ed., New Mexico: Albuquerque.

Luftman, J. \& Ben-Zvi, T. (2011). Key issues for IT executives 2011: Cautious optimism in uncertain economic times. MIS Quarterly Executive 10(4), 203-212.

Luftman, J. (2000). Assessing business-IT alignment maturity. Communications of the Association of Information Systems, 4(14), 1-50.

Luftman, J., \& Brier, T. (1999). Achieving and sustaining business-IT alignment. California Management Review, 42(1), 109-122.

Luftman, J., Lyytinen, K., \& Zvi, T. B. (2017). Enhancing the measurement of information technology (IT) business alignment and its influence on company performance. Journal of Information Technology, 32(1), 26-46.

Majstorović, D. (2016). (Un) doing feminism in (post)-Yugoslav media spaces. Feminist Media Studies, 16(6), 1093-1108.

Malyzhenkov, P. V., \& Ivanova, M. I. (2017). An architectural approach to IT-business alignment. Business Informatics, 3, 56-64.

Marrone, M., \& Kolbe, L. M. (2011). Uncovering ITIL claims: IT executives' perception on benefits and Business-IT alignment. Information Systems and e-Business Management, 9(3), 363-380.

Martin, K. D., Borah, A., \& Palmatier, R. W. (2017). Data privacy: Effects on customer and firm performance. Journal of Marketing, 81(1), 36-58. 
Mills, A. M., \& Smith, T. A. (2011). Knowledge management and organizational performance: a decomposed view. Journal of Knowledge Management, 15(1), 156-171.

Mitcham, C., \& Mackey, R. (Eds.). (1983). Philosophy and technology (Vol. 80). Simon and Schuster.

Mithas, S., Ramsubbu, N., \& Sambamurthy, V. (2011). How information management capability influences firm performance, MIS Quarterly, 35(1), 237-256.

Mosthaf, J., \& Wagner, H. T. (2016). The architect's role in business-IT alignment. International Journal of IT/Business Alignment and Governance (IJITBAG), 7(1), 36-49.

Naidoo, L. (2012). The Strategic Alignment Maturity of Business and Information Technology at Volkswagen South Africa (Doctoral dissertation, Rhodes University).

Navedo-Samper, T., Ferrer, E., \& Rivera-Ruiz, I. (2013). Moderating effects of human factors on IT-business alignment and IT effectiveness in modern firms. Journal of Knowledge Management, Economics and Information Technology, 3(2), 1-3

O'Reilly, M., Talsma, A., VanRiper, S., Kheterpal, S., \& Burney, R. (2006). An anesthesia information system designed to provide physician-specific feedback improves timely administration of prophylactic antibiotics. Anesthesia \& Analgesia, 103(4), 908-912.

Oroszo, J., Tarhini, A., Masa'deh, R., \&Tarhini, T. (2015). A framework of IS/Business Alignment management practices to improve the design of IT governance architectures. International Journal of Business and Management, 10(4), 1-12.

Rajhans, K. (2012). Effective organizational communication: A key to employee motivation and performance. Interscience Management Review, 2(2), 81-85.

Rath, M. (2018, April). An Analytical Study of Security and Challenging Issues in Social Networking as an Emerging Connected Technology. In Proceedings of 3rd International Conference on Internet of Things and Connected Technologies (ICIoTCT) (pp. 26-27).

Ravishankar, M. N., Pan, S. L., \& Leidner, D. E. (2011). Examining the strategic alignment and implementation success of a KMS: A subculture-based multilevel analysis. Information Systems Research, 22(1), 39-59.

Rezaei, J., Ortt, R., \& Trott, P. (2018). Supply chain drivers, partnerships and performance of high-tech SMEs: An empirical study using SEM. International Journal of Productivity and Performance Management, 67(4), 629-653.

Rigoni, D., Polezzi, D., Rumiati, R., Guarino, R., \& Sartori, G. (2010). When people matter more than money: an ERPs study. Brain research Bulletin, 81(4-5), 445-452.

Rufai, I. A. (2014). The impact of communication technologies on the performance of SMEs in a developing economy: Nigeria as a case study. The Electronic Journal of Information Systems in Developing Countries, 65(1), 1-22.

Rukmana, H. D., MM, S. M. P., \& SE, E. N. (2018). The Impact of Organization Communication on Employee Performance Through Employee's Work Motivation at Pt. Putri Panda Unit Ii Tulungagung, East Jawa, Indonesia. KnE Social Sciences, 211-227.

Sahin, F., \& Robinson, E. P. (2002). Flow coordination and information sharing in supply chains: review, implications, and directions for future research. Decision Sciences, 33(4), 505-536.

Santos, J. B., \& Brito, L. A. L. (2012). Toward a subjective measurement model for firm performance. BAR-Brazilian Administration Review, 9(SPE), 95-117.

Sekaran, U. (2003). Research Methods and Methodology for Business.

Sekaran, U., \& Bougie, R. (2016). Research methods for business: A skill building approach. John Wiley \& Sons.

Shamekh, F. R. (2008). Business-IT strategic alignment concept in theory and practice (Master's thesis).

Sher, P. J., \& Lee, V. C. (2004). Information technology as a facilitator for enhancing dynamic capabilities through knowledge management. Information \& management, 41(8), 933-945.

Sledgianowski, D., \& Luftman, J. (2005). IT-business strategic alignment maturity: A case study. Journal of Cases on Information Technology (JCIT), 7(2), 102-120.

Stamper, T. (2012). Measuring the correspondence between business-IT alignment and Poelen, E. J. S (2017). The Implications of BusinessIT Alignment for Business Value of IT.

Stuart, T. E. (2000). Interorganizational alliances and the performance of firms: a study of growth and innovation rates in a high-technology industry. Strategic Management Journal, 21(8), 791-811.

Tarhini, A., Arachchilage, N. A. G., \& Abbasi, M. S. (2015). A critical review of theories and models of technology adoption and acceptance in information system research. International Journal of Technology Diffusion (IJTD), 6(4), 58-77.

Teeratansirikool, L., Siengthai, S., Badir, Y., \& Charoenngam, C. (2013). Competitive strategies and firm performance: the mediating role of performance measurement. International Journal of Productivity and Performance Management, 62(2), 168-184.

Tippins, M. J., \& Sohi, R. S. (2003). IT competency and firm performance: is organizational learning a missing link?. Strategic Management Journal, 24(8), 745-761.

Wagner, H. T. (2014). Evolvement of business-IT alignment over time: A situated change perspective. Proceedings of the 47th Annual Hawaii International Conference on System Sciences. Honolulu, HI, (pp. 4366-4375).

Walekhwa, N. T. (2011) Effects of Strategic Business Partnerships between Equity Bank ltd and Its Partners on Marketing Decisions. Unpublished MBA project. Nairobi: University of Nairobi.

Ward, A. J., Brown, J. A., \& Rodriguez, D. (2009). Governance bundles, firm performance, and the substitutability and complementarity of governance mechanisms. Corporate Governance: An International Review, 17(5), 646-660.

Wen-Chih, Y. E. H., TSENG, M. H., \& Chun-Chang, L. E. E. (2017). The Relationship between Partnerships and Organizational Performance in the Industrial Waste Management Industry. DEStech Transactions on Environment, Energy and Earth Sciences, (eesd).

Young, S., \& Thyil, V. (2008). A holistic model of corporate governance: a new research framework. Corporate Governance: The International Journal of Business in Society, 8(1), 94-108.

Zikmund, W. G. (2003). Sample designs and sampling procedures. Business Research Methods, 7(2), 368-400.

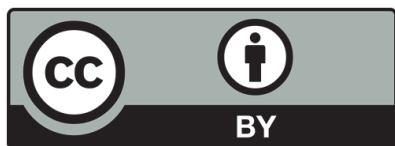

(C) 2021 by the authors; licensee Growing Science, Canada. This is an open access article distributed under the terms and conditions of the Creative Commons Attribution (CC-BY) license (http://creativecommons.org/licenses/by/4.0/). 